\title{
Polymorphisms in the type IV collagen $\alpha 3$ gene and the risk of COPD
}

\author{
K.M. Kim*, S.H. Park*, J.S. Kim*, W.K. Lee ${ }^{\#}$, S.I. Cha", C.H. Kim ", Y.M. Kang", \\ T.H. Jung", I.S. Kim* and J.Y. Park*,
}

ABSTRACT: A number of genome-wide linkage analyses have identified the 2q33.3-2q37.2 region as the most likely to contain the genes that contribute to the susceptibility to chronic obstructive pulmonary disease (COPD). It was hypothesised that the type IV collagen $\alpha 3$ (COL4A3) gene, which is one of the genes located in the 2q33.3-2q37.2 region, may act as a low-penetrance susceptibility gene for COPD.

To test this hypothesis, the association of COL4A3 $-1162 T>C$, IVS2 $+12 C>A, P 141 L, G 162 E$, H451R, P574L and *315C $>$ A polymorphisms with the risk of COPD was investigated in a casecontrol study of 311 COPD patients and 386 controls.

The presence of at least one 451R allele was associated with a significantly higher risk of COPD compared with the $451 \mathrm{H} / \mathrm{H}$ genotype (adjusted odds ratio 1.48, 95\% confidence interval (1.032.14)). When the subjects were stratified according to age and COPD severity, the 451R allele was associated with a significantly higher risk of COPD only in younger individuals with severe COPD (3.02 (1.37-6.67)).

In conclusion, these findings suggest that the type IV collagen $\alpha 3$ gene contributes to the genetic susceptibility to chronic obstructive pulmonary disease.

KEYWORDS: Chronic obstructive pulmonary disease, polymorphisms, susceptibility, type IV collagen $\alpha 3$

hronic obstructive pulmonary disease (COPD) is a disease characterised by progressive irreversible airflow obstruction due to the narrowing of small airways by inflammation, and loss of lung elastic recoil resulting from parenchymal destruction [1]. Cigarette smoking is the single most important environmental risk factor for the development of COPD but only a fraction of chronic smokers develop symptomatic COPD [2-4]. These observations, together with the familial clustering of COPD [5], suggest that genetic factors contribute to the development of COPD [6-8]. The genes related to the protease-antiprotease hypothesis, the oxidant-antioxidant hypothesis, inflammatory response, apoptosis and xenobiotic metabolism have been investigated based on the known or presumed pathophysiology of COPD, but the results were often inconsistent across studies [9].

A number of genome-wide linkage analyses have identified chromosomal regions that are likely to contain genes that contribute to the susceptibility to COPD [10-13]. The 2q33.3-2q37.2 region showed logarithm of the odds scores $>2.0$ for the ratio of forced expiratory volume in one second (FEV1) to forced vital capacity (FVC) in the Boston Early-Onset COPD Study families [10]. A similar region on chromosome $2 q$ was linked to the FEV1/FVC ratio in the families studied in the Utah Genetic Reference Project [12]. In addition, it has been suggested that the 2q33.3-2q37.2 region of linkage contains genes that contribute to COPD susceptibility through gene-smoking interactions [13]. This region harbours a number of candidate genes for COPD, including interleukin- 8 receptor- $\alpha$ and $-\beta$, cytochrome P450 family member CYP27A1, type IV collagen $\alpha 3$ (COL4A3) and solute carrier family 11 .

Of the positional candidate genes for COPD, the present authors investigated the potential role of the COL4A3 gene in the susceptibility to COPD. COL4A3, which is one of six genetically distinct homologous $\alpha$-chains (COL4 A1-A6), is abundantly expressed in normal alveolar basement membrane [14, 15]. It assembles into triple-helical collagen molecules with COL4A4 and COL4A5, and it plays a pivotal role in the regulation of cellular proliferation, adhesion, migration and differentiation [14, 15]. Moreover, COL4A3 can inhibit the activation of neutrophils. COL4A3 increases cytoplasmic
AFFILIATIONS

Depts of *Biochemistry,

\#Preventive Medicine, and

"Internal Medicine, Kyungpook

National University Hospital, Daegu, Republic of Korea.

CORRESPONDENCE

J.Y. Park

Dept of Internal Medicine

Kyungpook National University

Hospital

Samduk 2a 50

Daegu

700-412

Republic of Korea

Fax: 82534262046

E-mail: jaeyong@knu.ac.kr

Received:

June 222007

Accepted after revision:

March 132008

SUPPORT STATEMENT

This study was supported by the Korea Health 21 Research and Development Project, Ministry of Health and Welfare, Republic of Korea (grant no. A060165), and in part by the Brain Korea 21 Project in 2006.

STATEMENT OF INTEREST

None declared.

European Respiratory Journal Print ISSN 0903-1936 Online ISSN 1399-3003 
cyclic adenosine monophosphate in neutrophils, resulting in the inhibition of their superoxide production and proteinase secretion [16, 17]. In addition, several studies have demonstrated that COL4A3 can inhibit endothelial cell proliferation and induce cell apoptosis [18, 19]. Taken together, these findings suggest that COL4A3 may be involved in the development of COPD by modulating the inflammatory response or alveolar wall apoptosis [20-22].

Several polymorphisms in the COL4A3 gene have been deposited into public databases [23]. Although the functional effects of these polymorphisms have not yet been fully elucidated, the current authors hypothesised that some of these variants may have an effect on COL4A3 expression or activity and, therefore, may play a role in modulating the susceptibility to COPD. To test this hypothesis, a case-control study was performed to investigate the association between COL4A3 genotypes/haplotypes and the risk of COPD.

\section{MATERIALS AND METHODS}

\section{Identification and selection of polymorphisms}

In order to screen all the potentially functional variants in the COL4A3 gene, the public database [23] was used to search for candidate variants in the promoter region, all exons (including intron-exon boundaries, $20 \mathrm{bp}$ on either side of the introns) and the 3 -untranslated region of the gene, since variants in these regions are most likely to affect the gene function. In total, seven polymorphisms were studied: $-1162 \mathrm{~T}>\mathrm{C}$ (rs12613226), IVS2+12C >A (rs1882435), P141L (in exon 7; rs10178458), G162E (in exon 7; rs6436669), H451R (in exon 22; rs11677877), P574L (in exon 25; rs28381984) and *315C $>$ A (rs2070735). The transcription start site was counted as +1 and the nucleotide $3^{\prime}$ of the translation termination codon was denoted by ${ }^{*} 1$ [24]. The polymorphism frequencies were determined by direct sequencing in a preliminary study that included 27 healthy Korean individuals. The samples were collected after obtaining informed consent from each

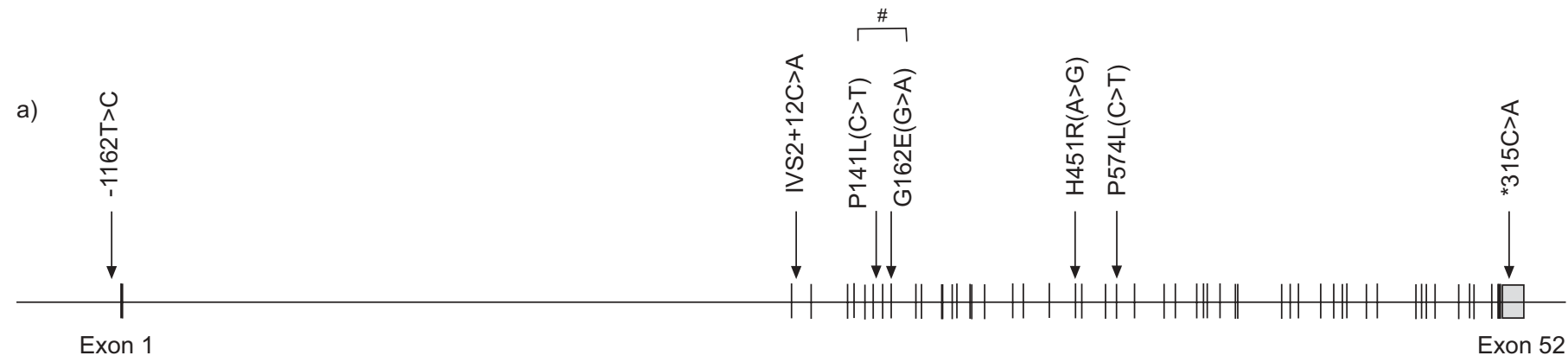

b)

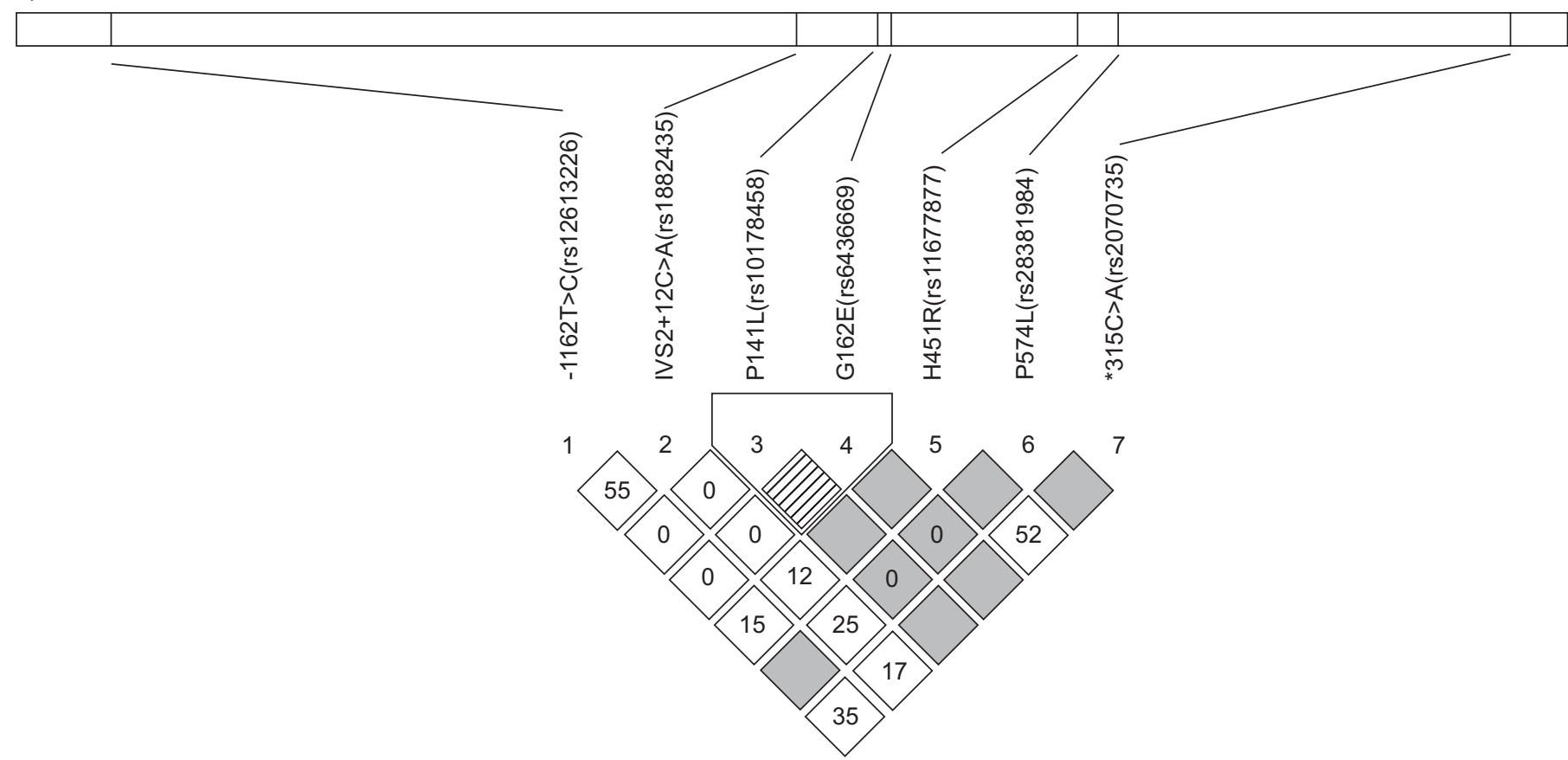

FIGURE 1. Gene map, polymorphisms and linkage disequilibrium (LD) coefficients. a) Gene map and polymorphisms in the type IV collagen $\alpha 3$ (COL4A3) gene on chromosome 2q36-q37. The transcription start site was counted as $+1 .{ }^{\star} 315 \mathrm{C}>\mathrm{A}$ : nucleotide $3153^{\prime}$ of the translation termination codon [24]. The reference genomic sequence was NT_005403, total gene size is $15,023 \mathrm{~kb}$. 口 : coding exons; 1 : $3^{\prime}$-untranslated region (UTR). * : $\left|\mathrm{D}^{\prime}\right|=1.00, \mathrm{r}^{2}=1.00$. b) LD block showing $\left|\mathrm{D}^{\prime}\right|(\times 100)$ values between COL4A3 polymorphisms in 27 healthy Koreans. Polymorphisms 3 and 4 form a haplotype block. $\mathbb{Z}$ : complete $L D\left(\left|D^{\prime}\right|=1.00, r^{2}=1.00\right) ; \square:$ strong recombination (upper confidence limit $\leqslant 0.9$ ); $\square$ : uninformative findings. 
individual and included 54 chromosomes, providing at least a $95 \%$ confidence level to detect alleles with frequencies $>5 \%$. The primer sets used for sequencing were designed based on the GenBank reference sequence (accession no. NT_005403). The sequence variants were confirmed by two independent authors. Information regarding all single nucleotide polymorphisms (SNPs), SNP IDs and allele frequencies was obtained from the National Center for Biotechnology Information dbSNP homepage [23]. The seven SNPs examined had minor allele frequencies $>10 \%$ in the 27 subjects. The P141L and G162E polymorphisms were in complete linkage disequilibrium (LD), with $\left|\mathrm{D}^{\prime}\right|=1.00$ and $\mathrm{r}^{2}=1.00$. Therefore, six SNPs were chosen for the association study: $-1162 \mathrm{~T}>\mathrm{C}$, IVS2+12C $>$ A, G162E, H451R, P574L and *315C $>$ A (fig. 1).

\section{Study population}

The patient group consisted of 311 male COPD patients who visited the respiratory centre of the Kyungpook National University Hospital (Daegu, Republic of Korea) between July 2006 and December 2006. COPD was diagnosed according to the criteria established by the National Heart, Lung, and Blood Institute/World Health Organization Global Initiative for Chronic Obstructive Lung Disease (GOLD) [1]. The criteria for COPD were as follows: chronic respiratory symptoms and signs, such as cough and dyspnoea; post-bronchodilator FEV1 $<80 \%$ of the predicted value; FEV1/FVC $<70 \%$; and $\mathrm{FEV} 1$ reversibility after inhaling $200 \mu \mathrm{g}$ salbutamol $<12 \%$ of the prebronchodilator FEV1. The severity of COPD was classified by the FEV1 \% predicted, according to the guidelines established by the GOLD: mild $(>80 \%)$, moderate $(50-80 \%)$, severe $(30-$ $50 \%)$ or very severe $(<30 \%)$. The 386 control subjects were recruited from 765 males who visited the health check-up centre at Kyungpook National University Hospital during the same period. The enrolment criteria for the controls were as follows: age $>45$ yrs; no known disease and no history of any disease; and no airflow limitation. A total of 386 out of 718 males who met these criteria agreed to participate in this study (participation rate $53.8 \%$ ). Compared with the subjects that refused to participate, the enrolled subjects showed a similar age distribution and smoking exposure level. All the cases and controls were ethnic Koreans and they resided in Daegu City or the surrounding regions.

\section{LightCycler genotyping}

The genotypes of the six polymorphisms were determined by PCR and melting-curve analysis using fluorescence-labelled hybridisation probes (LightCycler; Roche Diagnostics, Mannheim, Germany). A genotype success rate of $>98 \%$ was achieved using Förster/fluorescence resonance energy transfer (FRET). Samples that could not be scored by FRET were regenotyped by direct sequencing using an ABI PRISM 3700 genetic analyser (Applied Biosystems, Foster City, CA, USA). All genotyping analyses were performed "blind" with respect to the case/control status in order to ensure quality control. In addition, $\sim 10 \%$ of the samples were randomly selected to be genotyped again by a different investigator and the results were $100 \%$ concordant.

\section{Statistical analysis}

The cases and controls were compared using an unpaired t-test for continuous variables and a Chi-squared test for categorical variables. Hardy-Weinberg equilibrium was tested using a goodness-of-fit Chi-squared test with one degree of freedom. The strength of LD between pairs of polymorphisms was measured as $\mathrm{D}^{\prime}$ and $\mathrm{r}^{2}$ by Haploview [25]. LD blocks were inferred from the definition proposed by GABRIEL et al. [26]. Unconditional logistic regression analysis was used to calculate odds ratios (ORs) and 95\% confidence intervals (CIs), with adjustment for possible confounders (age and pack-yrs of smoking as continuous variables). In addition to the overall association analysis, a stratified analysis according to age and COPD severity was performed in order to further explore the association between COL4A3 genotypes and the risk of COPD in each stratum. For the gene-smoking interaction analyses, three approaches were used to evaluate the consistency of the results: 1) stratified analyses in specific categories of cumulative smoking exposure; 2) joint genotype/haplotype-smoking effects; and 3) a logistic regression model including the interaction term between genotype and smoking. In the regression model, smoking was considered as both a discrete and continuous variable as follows: 1) pack-yrs of smoking, 2) square root of pack-yrs; and 3) smoking exposure level, categorised as never-smoker, lighter smoker or heavier smoker. Since the interaction term was not statistically significant in any of these models, the result was only presented when the continuous cumulative smoking dose (pack-yrs of smoking) was used in the analysis. For these analyses, ever-smokers in both groups were categorised into two subgroups according to the median pack-yr value: eversmokers $\leqslant 33$ pack-yrs were denoted lighter smokers and eversmokers $>33$ pack-yrs were denoted heavier smokers.

\section{RESULTS}

The baseline characteristics of the cases and controls enrolled in the present study are shown in table 1 . The FEV1 and FEV1/ FVC ratio were significantly lower in the COPD group than in the control group.

The genotype and polymorphic allele frequencies of the six COL4A3 polymorphisms in the cases and controls are shown in table 2. The genotype distributions of the six polymorphisms

\begin{tabular}{|c|c|c|c|}
\hline & COPD & Control & $p$-value \\
\hline Subjects $n$ & 311 & 386 & \\
\hline Age yrs & $65.5 \pm 8.1$ & $60.4 \pm 8.0$ & $<0.001^{\#}$ \\
\hline Smoking status $\mathrm{n}(\%)$ & & & $<0.001^{\circ}$ \\
\hline Current & $171(55.0)$ & 205 (53.1) & \\
\hline Former & $129(41.5)$ & $128(33.2)$ & \\
\hline Never & $11(3.5)$ & $53(13.7)$ & \\
\hline Smoking pack-yrs ${ }^{+}$ & $42.6 \pm 20.0$ & $30.8 \pm 16.9$ & $<0.001^{\circ}$ \\
\hline FEV $1 \%$ pred & $63.4 \pm 26.3$ & $104.9 \pm 16.8$ & $<0.001^{\circ}$ \\
\hline FEV1/FVC \% & $49.7 \pm 13.1$ & $80.7 \pm 7.4$ & $<0.001^{\bullet}$ \\
\hline
\end{tabular}

Data are presented as mean $\pm \mathrm{SD}$, unless otherwise stated. All cases and controls were male ethnic Koreans. COPD: chronic obstructive pulmonary disease; FEV1: forced expiratory volume in one second; \% pred: \% predicted FVC: forced vital capacity. ${ }^{*}$ : t-test; ${ }^{~}$ : Chi-squared test; ${ }^{+}$: in current and former smokers 


\begin{tabular}{|c|c|c|c|c|c|c|c|c|c|c|}
\hline \multirow[t]{2}{*}{ SNP } & \multirow[t]{2}{*}{ SNP ID } & \multirow[t]{2}{*}{ Genotype } & \multirow[t]{2}{*}{ Cases n (\%) } & \multirow[t]{2}{*}{ Controls n (\%) } & \multirow[t]{2}{*}{ p-value ${ }^{\#}$} & \multicolumn{3}{|c|}{ Minor allele frequency } & \multirow{2}{*}{$\begin{array}{l}\text { Adjusted OR } \\
(95 \% \mathrm{Cl})^{\circ}\end{array}$} & \multirow[t]{2}{*}{ p-value } \\
\hline & & & & & & Cases & Controls & p-value $\#$ & & \\
\hline \multirow[t]{2}{*}{$-1162 T>C$} & rs12613226 & $\pi$ & $154(49.5)$ & 191 (49.5) & 0.91 & 0.30 & 0.30 & 0.85 & 1.00 & \\
\hline & & $\mathrm{CC}$ & $27(8.7)$ & $37(9.6)$ & & & & & $0.99(0.55-1.80)$ & 0.98 \\
\hline \multirow[t]{3}{*}{ IVS2+12C $>A$} & rs1882435 & $\mathrm{CC}$ & $101(32.5)$ & $135(35.0)$ & 0.79 & 0.42 & 0.41 & 0.54 & 1.00 & \\
\hline & & CA & $157(50.5)$ & $188(48.7)$ & & & & & $1.20(0.83-1.73)$ & 0.33 \\
\hline & & AA & $53(17.0)$ & $63(16.3)$ & & & & & $1.18(0.72-1.93)$ & 0.51 \\
\hline \multirow[t]{2}{*}{ G162E $(G>A)$} & rs6436669 & GG & $241(77.5)$ & 307 (79.5) & 0.35 & 0.12 & 0.11 & 0.74 & 1.00 & \\
\hline & & GE & 68 (21.9) & 73 (18.9) & & & & & $1.11(0.74-1.67)$ & 0.62 \\
\hline \multirow{2}{*}{ H451R $(A>G)$} & & $\mathrm{HH}$ & $213(68.5)$ & $294(76.2)$ & 0.02 & & & & 1.00 & \\
\hline & & $\mathrm{HR}+\mathrm{RR}$ & 98 (31.5) & $92(23.8)$ & & & & & $1.48(1.03-2.14)$ & 0.03 \\
\hline \multirow[t]{3}{*}{ P574L $(C>T)$} & rs28381984 & PP & $86(27.7)$ & $123(31.9)$ & 0.32 & 0.46 & 0.44 & 0.60 & 1.00 & \\
\hline & & PL & $165(53.1)$ & $183(47.4)$ & & & & & $1.39(0.95-2.04)$ & 0.09 \\
\hline & & LL & $60(19.3)$ & $80(20.7)$ & & & & & $1.25(0.78-2.01)$ & 0.98 \\
\hline \multirow[t]{3}{*}{$\star 315 \mathrm{C}>\mathrm{A}^{+}$} & rs2070735 & $\mathrm{CC}$ & $187(60.1)$ & $220(57.0)$ & 0.63 & 0.22 & 0.24 & 0.35 & 1.00 & \\
\hline & & CA & $112(36.0)$ & $147(38.1)$ & & & & & $0.88(0.62-1.24)$ & 0.46 \\
\hline & & AA & $12(3.9)$ & $19(4.9)$ & & & & & $0.55(0.24-1.26)$ & 0.16 \\
\hline
\end{tabular}

SNP: single nucleotide polymorphism; OR: odds ratio; Cl: confidence interval. ${ }^{*}$ : two-sided Chi-squared test between the cases and controls; ": calculated by unconditional logistic analysis, adjusted for age and pack-yrs of smoking; ${ }^{+}$: nucleotide $3153^{\prime}$ of the translation termination codon.

TABLE 3 Association between type IV collagen $\alpha 3$ H451R (rs11677877A>G) genotypes and the risk of chronic obstructive pulmonary disease (COPD)

\begin{tabular}{|c|c|c|c|c|c|c|c|}
\hline \multirow[t]{2}{*}{ Variables } & \multicolumn{2}{|c|}{ Cases } & \multicolumn{2}{|c|}{ Controls } & \multirow[t]{2}{*}{ Adjusted OR $(95 \% \mathrm{Cl})^{\#}$} & \multirow[t]{2}{*}{$p$-value } & \multirow[t]{2}{*}{ p-value } \\
\hline & HH & HR+RR & $\mathrm{HH}$ & HR+RR & & & \\
\hline \multicolumn{8}{|l|}{ Age yrs } \\
\hline$\leqslant 60$ & $51(61.4)$ & $32(38.6)$ & $155(76.4)$ & 48 (23.6) & $1.93(1.10-3.39)^{5}$ & 0.02 & 0.10 \\
\hline$>60$ & $162(71.1)$ & $66(28.9)$ & $139(76.0)$ & $44(24.0)$ & $1.25(0.78-2.01)^{\S}$ & 0.35 & \\
\hline Ever $^{+}$ & $205(68.3)$ & $95(31.7)$ & $254(76.3)$ & 79 (23.7) & $1.57(1.08-2.27)^{f}$ & 0.02 & 0.29 \\
\hline \multicolumn{8}{|l|}{ Smoking pack-yrs ${ }^{+}$} \\
\hline$\leqslant 33$ & $69(74.2)$ & $24(25.8)$ & $151(76.3)$ & $47(23.7)$ & $1.15(0.65-2.06)^{f}$ & 0.63 & \\
\hline$>33$ & $136(65.7)$ & 71 (34.3) & $103(76.3)$ & $32(23.7)$ & $1.84(1.10-3.08)^{f}$ & 0.02 & 0.09 \\
\hline \multicolumn{8}{|l|}{ Severity of COPD } \\
\hline GOLD I-II & $138(69.7)$ & $60(30.3)$ & $294(76.2)$ & $92(23.8)$ & $1.33(0.88-2.01)^{\text {s.f }}$ & 0.18 & \\
\hline$>60$, GOLD I-II & $103(70.5)$ & $43(29.5)$ & $139(76.0)$ & $44(24.0)$ & $1.25(0.75-2.10)^{5}$ & 0.39 & \\
\hline$>60$, GOLD III-IV & $59(72.0)$ & $23(28.0)$ & $139(76.0)$ & $44(24.0)$ & $1.31(0.69-2.49)^{\S}$ & 0.40 & \\
\hline
\end{tabular}

Data are presented as $\mathrm{n}(\%)$, unless otherwise stated. OR: odds ratio; Cl: confidence interval; GOLD: Global Initiative for Chronic Obstructive Lung Disease. \#: for HR+RR

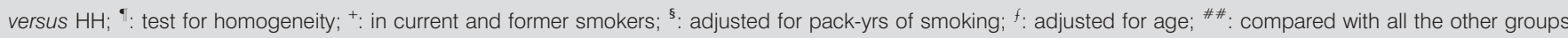
combined. 


\begin{tabular}{|c|c|c|c|c|c|c|}
\hline TABLE 4 & of type I & llagen $\alpha 3$ & Renotypes and toba & smoking & the risk of & ic obstructive pulmonary \\
\hline \multirow[t]{2}{*}{ Smoking status } & \multicolumn{3}{|c|}{ Genotype HH } & \multicolumn{3}{|c|}{ Genotype HR+RR } \\
\hline & Cases $\mathbf{n}$ & Controls n & Adjusted OR $(95 \% \mathrm{Cl})^{\#}$ & Cases n & Controls n & Adjusted OR $(95 \% \mathrm{Cl})^{\#}$ \\
\hline Never-smoker & 8 & 40 & 1.00 & 3 & 13 & $1.23(0.27-5.47)$ \\
\hline \multicolumn{7}{|l|}{ Smoker pack-yrs } \\
\hline$\leqslant 33$ & 69 & 151 & $2.40(1.05-5.49)^{\bullet}$ & 24 & 47 & $2.79(1.11-7.05)^{\dagger}$ \\
\hline$>33$ & 136 & 103 & $5.36(2.37-12.13)^{\star \star \star}$ & 71 & 32 & $9.51(3.93-23.01)^{\star * \star}$ \\
\hline
\end{tabular}

in the controls were in Hardy-Weinberg equilibrium. The frequency of the polymorphic allele at H451R was significantly higher in the cases than in the controls ( 0.17 versus 0.13 ; $\mathrm{p}=0.02$ ). Individuals with at least one $451 \mathrm{R}$ allele were at a significantly higher risk of COPD compared with carriers of the $451 \mathrm{HH}$ genotype (adjusted OR 1.48, 95\% CI (1.03-2.14); $\mathrm{p}=0.03$ ). The genotype distributions of the other five polymorphisms studied were not significantly different between the cases and controls.

The association of the H451R genotypes with the risk of COPD was further examined after stratifying the subjects according to age, smoking status and the severity of COPD (table 3). When stratified by median age, the HR or RR genotype was associated with a significantly increased risk of COPD in younger individuals (adjusted OR 1.93, 95\% CI (1.10-3.39); $\mathrm{p}=0.02)$; however, there was no significant association between these genotypes and risk of COPD in older individuals. When stratified according to smoking status, the effect of the HR or RR genotype on the risk of COPD was significant in the smokers $(1.57(1.08-2.27) ; \mathrm{p}=0.02)$ but not in the neversmokers. When the ever-smokers were dichotomised by median pack-yrs of smoking, the effect of the HR or RR genotype on the risk of COPD was significant in the heavier smokers (1.84 (1.10-3.08); $\mathrm{p}<0.02)$, whereas there was no significant association between these genotypes and risk of COPD in the lighter smokers. When the COPD cases were categorised by COPD severity, the presence of one or two 451R alleles was associated with a significantly increased risk of severe COPD (GOLD stage III-IV; adjusted OR 1.62, 95\% CI $(1.00-2.61) ; p=0.04)$, whereas there was no significant association between the H451R genotypes and the risk of mild-tomoderate COPD (GOLD stage I-II). When age and COPD severity were considered together, the effect of the HR or RR genotype was only significant in the younger individuals with severe COPD (3.02 (1.37-6.67); $p=0.006 ; p=0.001$ in test for homogeneity).

In addition to the stratification analyses, the joint effects of the H451R genotypes and smoking status on the risk of COPD were also investigated (table 4 ). When the group of neversmokers with the $\mathrm{HH}$ genotype was used as the reference group, the group of heavier smokers with the HR or RR genotype was found to have the highest risk of COPD (adjusted OR 9.51, 95\% CI (3.93-23.01); p<0.001).
Nevertheless, no statistically significant evidence for interactions was observed between the H451R genotypes and the continuous cumulative smoking dose in the multivariate logistic regression analysis ( $p=0.32$ for the interaction term).

\section{DISCUSSION}

In the present study, the potential association between polymorphisms in the COL4A3 gene and the risk of COPD was investigated in a Korean population. The H451R polymorphism was associated with a significantly increased risk of COPD. The association between the H451R genotypes and risk of COPD was more evident in younger individuals and in patients with severe COPD. These findings suggest that the COL4A3 gene may be involved in the development of COPD and that the H451R polymorphism in the COL4A3 gene may be a useful marker for genetic susceptibility to COPD.

The COL4A3 H451R polymorphism interacted with tobacco smoking in determining the risk of COPD in the present study. The HR or RR genotype was significantly associated with the risk of COPD in the smokers but not in the never-smokers, which reflects a gene-environment interaction. Such an interaction is biologically plausible, since smoking is known to be a major cause of COPD. Another interesting finding of the current study is that the H451R polymorphism had a more pronounced association with severe COPD in the younger patients, which is consistent with the notion that genetic factors can play a major role in the early onset of disease [10, 11]. Individuals with aberrant $C O L 4 A 3$ activity may be more prone to developing COPD at a younger age; thus, the association would be more clearly observed in younger patients with severe COPD.

It remains to be elucidated whether the COL4A3 H451R polymorphism itself affects protein folding, interaction sites, solubility or stability of the protein or whether it is in LD with either another $\mathrm{COL} 4 A 3$ variant or an adjacent true susceptibility gene. Several computational algorithms have been introduced to predict the effect of nonsynonymous SNPs (nsSNPs) on protein structure or function [27]. The PolyPhen algorithm was developed to identify functionally important nsSNPs by predicting whether an amino acid change is likely to be deleterious to the protein on the basis of the threedimensional structure and multiple alignments of homologous sequences [28]. ZHU et al. [29] applied PolyPhen to 166 molecular epidemiological studies in order to examine the 
correlation between position-specific independent counts (PSIC) score and the OR associated with a particular nsSNP. Significant inverse correlations were found between the OR and the PSIC score difference and between the tolerance index and the PSIC score difference. These results indicate that PolyPhen is helpful in predicting the functional significance of the nsSNP. PolyPhen was also used in the present study to infer the functional relevance of the three COL4A3 nsSNPs studied: G162E, H451R and P574L. This showed that the H451R polymorphism was the only one that may possibly be damaging, which is consistent with the finding that the $451 \mathrm{R}$ allele was associated with a significantly increased risk for COPD. This finding is, therefore, biologically plausible.

The interpretation of the current data is limited by the lack of published evidence showing that COL4A3 protein contributes to the development of COPD. The pathological hallmarks of COPD are small airway inflammation and emphysema. One of the most prevailing hypotheses for the pathogenesis of emphysema is an inflammatory cell theory, which suggests that cigarette smoke stimulates inflammatory cells, such as neutrophils and macrophages, to release proteinases that lead to the disruption of the extracellular matrix (ECM) and basement membrane [1, 20,30]. An alternative hypothesis is an apoptosis theory, which suggests that cigarette smoke decreases the expression of vascular endothelial growth factor (VEGF) and VEGF receptor-2, resulting in epithelial and endothelial apoptosis with subsequent loss of ECM components and alveolar units [23, 31]. COL4A3 has been shown to inhibit the activation of neutrophils and thereby decrease their secretion of superoxide and proteinases, including elastase and type IV collagenase [16, 17]. In addition, several studies have demonstrated that the noncollagenous domain of COL4A3 inhibits angiogenesis by interacting with integrins, leading to cell apoptosis [18, 19]. Therefore, it is possible that COL4A3 may be involved in the degradation of the basement membrane and ECM by modulating either the inflammatory response or apoptosis and, thus, contribute to the development of COPD. However, this hypothesis must be verified in future studies.

COL4A3 polymorphisms may have an influence on disease progression. However, in the present study, there was no significant difference in the genotype distributions of COL $4 A 3$ polymorphisms according to the severity of COPD. In addition, the COL4A3 genotypes were not significantly associated with the quantitative lung function measures (data not shown).

In conclusion, the type IV collagen $\alpha 3 \mathrm{H} 451 \mathrm{R}$ polymorphism was significantly associated with the risk of chronic obstructive pulmonary disease. This association appeared to be influenced by tobacco smoking. The effect of the polymorphism on the risk of chronic obstructive pulmonary disease was more pronounced in younger patients with severe chronic obstructive pulmonary disease. These results suggest that the type IV collagen $\alpha 3$ gene may contribute to a genetic predisposition to chronic obstructive pulmonary disease by influencing the response to cigarette smoke exposure through a gene-smoking interaction. However, since this was the first case-control study investigating the associations between type IV collagen $\alpha 3$ polymorphisms and the risk of chronic obstructive pulmonary disease, additional studies are required to confirm the findings. Moreover, further study is needed to define a functional role for type IV collagen $\alpha 3$ in chronic obstructive pulmonary disease.

\section{REFERENCES}

1 Pauwels RA, Buist AS, Calverley PM, Jenkins CR, Hurd SS, GOLD Scientific Committee. Global strategy for the diagnosis, management, and prevention of chronic obstructive pulmonary disease. NHLBI/WHO Global Initiative for Chronic Obstructive Lung Disease (GOLD) Workshop summary. Am J Respir Crit Care Med 2001; 163: 1256-1276.

2 Fletcher C, Peto R. The natural history of chronic airflow obstruction. Br Med J 1977; 1: 1645-1648.

3 Burrows B, Knudson RJ, Cline MG, Lebowitz MD. Quantitative relationships between cigarette smoking and ventilatory function. Am Rev Respir Dis 1977; 115: 195-205.

4 Løkke A, Lange P, Scharling H, Fabricius P, Vestbo J. Developing COPD: a 25 year follow up study of the general population. Thorax 2006; 61: 935-939.

5 Kueppers F, Miller RD, Gordon H, Hepper NG, Offord K. Familial prevalence of chronic obstructive pulmonary disease in a matched pair study. Am J Med 1977; 63: 336-342.

6 Bascom R. Differential susceptibility to tobacco smoke: possible mechanisms. Pharmacogenetics 1991; 1: 102-106.

7 Silverman EK, Chapman HA, Drazen JM, et al. Genetic epidemiology of severe, early-onset chronic obstructive pulmonary disease. Risk to relatives for airflow obstruction and chronic bronchitis. Am J Respir Crit Care Med 1998; 157: 1770-1778.

8 Joos L, Paré PD, Sandford AJ. Genetic risk factors of chronic obstructive pulmonary disease. Swiss Med Wkly 2002; 132: 27-37.

9 Hersh CP, DeMeo DL, Lange C, et al. Attempted replication of reported chronic obstructive pulmonary disease candidate gene associations. Am J Respir Cell Mol Biol 2005; 33: 71-78.

10 Silverman EK, Palmer LJ, Mosley JD, et al. Genomewide linkage analysis of quantitative spirometric phenotypes in severe early-onset chronic obstructive pulmonary disease. Am J Hum Genet 2002; 70: 1229-1239.

11 Palmer LJ, Celedón JC, Chapman HA, Speizer FE, Weiss ST, Silverman EK. Genome-wide linkage analysis of bronchodilator responsiveness and post-bronchodilator spirometric phenotypes in chronic obstructive pulmonary disease. Hum Mol Genet 2003; 12: 1199-1210.

12 Malhotra A, Peiffer AP, Ryujin DT, et al. Further evidence for the role of genes on chromosome 2 and chromosome 5 in the inheritance of pulmonary function. Am J Respir Crit Care Med 2003; 168: 556-561.

13 DeMeo DL, Celedón JC, Lange C, et al. Genome-wide linkage of forced mid-expiratory flow in chronic obstructive pulmonary disease. Am J Respir Crit Care Med 2004; 170: 1294-1301.

14 Boutaud A, Borza DB, Bondar O, et al. Type IV collagen of the glomerular basement membrane. Evidence that the chain specificity of network assembly is encoded by the noncollagenous NC1 domains. J Biol Chem 2000; 275: 30716-30724. 
15 Saito K, Naito I, Seki T, et al. Differential expression of mouse $\alpha 5(\mathrm{IV})$ and $\alpha 6(\mathrm{IV})$ collagen genes in epithelial basement membranes. J Biochem 2000; 128: 427-434.

16 Monboisse JC, Garnotel R, Bellon G, et al. The $\alpha 3$ chain of type IV collagen prevents activation of human polymorphonuclear leukocytes. J Biol Chem 1994; 269: 25475-25482.

17 Shahan TA, Ziaie Z, Pasco S, et al. Identification of CD47/ integrin-associated protein and $\alpha \mathrm{v} \beta 3$ as two receptors for the $\alpha 3$ (IV) chain of type IV collagen on tumor cells. Cancer Res 1999; 59: 4584-4590.

18 Maeshima Y, Yerramalla UL, Dhanabal M, et al. Extracellular matrix-derived peptide binds to $\alpha \mathrm{v} \beta 3$ integrin and inhibits angiogenesis. J Biol Chem 2001; 276: 3195931968.

19 Marneros AG, Olsen BR. The role of collagen-derived proteolytic fragments in angiogenesis. Matrix Biol 2001; 20: 337-345.

20 Groneberg DA, Chung KF. Models of chronic obstructive pulmonary disease. Respir Res 2004; 5: 18.

21 Kasahara Y, Tuder RM, Taraseviciene-Stewart L, et al. Inhibition of VEGF receptors causes lung cell apoptosis and emphysema. J Clin Invest 2000; 106: 1311-1319.

22 Aoshiba K, Yokohori N, Nagai A. Alveolar wall apoptosis causes lung destruction and emphysematous changes. Am J Respir Cell Mol Biol 2003; 28: 555-562.
23 National Center for Biotechnology Information dbSNP homepage. www.ncbi.nlm.nih.gov/SNP Date last updated: January 8, 2007. Date last accessed: June 25, 2006.

24 den Dunnen JT, Antonarakis SE. Nomenclature for the description of human sequence variations. Hum Genet 2001; 109: 121-124.

25 Haploview. http://broad.mit.edu/mpg/haploview Date last updated: August 21, 2007. Date last accessed: June 10, 2007.

26 Gabriel SB, Schaffner SF, Nguyen H, et al. The structure of haplotype blocks in the human genome. Science 2002; 296: 2225-2229.

27 Rebbeck TR, Spitz M, Wu X. Assessing the function of genetic variants in candidate gene association studies. Nat Rev Genet 2004; 5: 589-597.

28 Sunyaev S, Ramensky V, Koch I, Lathe W 3rd, Kondrashov AS, Bork P. Prediction of deleterious human alleles. Hum Mol Genet 2001; 10: 591-597.

29 Zhu Y, Spitz MR, Amos CI, Lin J, Schabath MB, Wu X. An evolutionary perspective on single-nucleotide polymorphism screening in molecular cancer epidemiology. Cancer Res 2004; 64: 2251-2257.

30 Snider GL. Chronic obstructive pulmonary disease: risk factors, pathophysiology and pathogenesis. Annu Rev Med 1989; 40: 411-429.

31 Shapiro SD. Vascular atrophy and VEGFR-2 signaling: old theories of pulmonary emphysema meet new data. J Clin Invest 2000; 106: 1309-1310. 